\title{
SISTEM TATAKELOLA GRUP RAPA'I DABOH BUNGONG JEUMPA BANTIMOH DI KAWASA PEMUKIMAN PASCA TSUNAMI ACEH, CARE, KOTA JANTHO
}

\author{
Rika Wirandi $^{1^{*},}$ Magfhirah Murni Bintang Permata ${ }^{2 *}$, Berlian Denada $^{3 *}$
}

\author{
Jurusan Seni Pertunjukan \\ Institut Seni Budaya Indonesia (ISBI) Aceh \\ Jl. Transmigrasi, Gampong Bukit Meusara, Kec. Kota Jantho,Kab. Aceh Besar, Kode Pos 23911 \\ Aceh. Indonesia \\ Email:rikawirandi@isbiaceh.ac.id, firafatir04@gmail.com,berliandenada@isbiaceh.ac.id
}

\begin{abstract}
Abstrak
Penelitian ini berjudul "Sistem Tatakelola Grup Rapa'iDaboh Bungong Jeumpa Bantimoh di Kawasan Pengungsian Pasca Tsunami, CARE, Kota Jantho". Penelitian ini bertujuan untuk mengetahui sistem tatakelola yang diterapkan dalam Grup Rapa'i Daboh Bungong Jeumpa Bantimoh (GRDBJB), yang dikaitkan dengan bagaimana suatu kelompok kesenian tradisional mampu bertahan dan berkembang oleh suatu mas yarakat ditengah perubahan sosio-geografis dan ekonomi, yang semulanya menetap di Pulau Aceh kemudian berpindah ke kawasan pengungsian Pasca Tsunami Aceh, CARE, di Kota Jantho. Memfokuskan padakajian bentuk tatakelola, dengan meng ambil topik bahasan sistem pengelolaan yang meliputi: pembentukan grup; sistem pengurusan; kepemimpinan; evaluasi kinerja; pengelolaan keuangan; sistem pewarisan rekrutmen dan pelatihan; dan strategi pertunjukan/ promosi/ pemasaran. Menggunakan pendekatan sistem pelembagaan seni dan sistem pengelolaan seni dari Jazuli. Metode penelitian yang digunakan dalam rencana penelitian ini nantinya dalah metode penelitian kualitatif sebagai prosedur penelitian yang menghasilkan data deskriptif berupa kata-kata tertulis dari orangorang dan perilaku yang dapat diamati dengan meng gunakan beberapa tahapan pengumpulan data yaitu: observasi; studi pustaka; wawancara; dan dokumentasi. Penelitian ini menyimpulkan bahwa, GRDBJB dibentuk atas alasan pembinaan dan pengembangan dengan tujuan pemeliharaan, penyelamatan, pelestarian, pengelolaan dan termasuk di dalammnya adalah upaya memberikan bimbingan, pengarahan, penggalian, pencatatan, dan peningkatan kualitas dari kalangan orang tua y ang merupakan seniman pelaku kesenian rapa'i yang tergabung dalam GRDBJB. Sistem pengelolaan atau tatakelola GRDBJB didasari oleh sistem pengelolaan semi-profesional berbasis kolektif-partisipatif-domokratis masyarakat dusun CARE. GRDBJB merupakan grup asuh atau grup cabang yang diben tuk dengan tujuan pelestarian dan pewarisan kepada generasi muda CARE yang berorientasi pada sistem pengelolaan non-komersil dan orientasi sosial.
\end{abstract}

Kata Kunci: tatakelola, rapa'i daboh, GRDBJB, CARE.

\begin{abstract}
This research is entitled "Management System of the Rapa'i Daboh Bungong Jeumpa Bantimoh Group in the Post-Tsunami Refugee Area, CARE, Jantho City". This study aims to determine the governance system applied in the Rapa'i Daboh Bungong Jeumpa Bantimoh Group (GRDBJB), which is associated with how a traditional art group is able to survive and develop by a society in the midst of sociogeographic and economic changes, which originally settled in The island of Aceh then moved to the post-Tsunamirefugee area in Aceh, CARE, in the City of Jantho. Focusing on the study of governance forms, taking the topic ofmanagement systems which include: group formation; management system; leadership; performance evaluation; financial management; recruitment and training inheritance system; and performance / promotion / marketing strategy. Using the approach of art institutionalization systems and art management systems from Jazuli. The research method used in this research plan is a qualitative research method as a research procedure that produces descriptive data in the form of written words from people and behavior that can be observed using several stages of data collection, namely: observation; literature review; Interview; and documentation. This study concludes that GRDBJB was formed for the reason of coaching and development with the aim of maintaining, saving, preserving, managing and including efforts to provide guidance, direction, excavation, recording, and quality improvement among parents who are artists who do the art of rapa ' $i$ who is a member of GRDBJB. The GRDBJB managementor governance system is based on a semi-professional management system based on the collective-participatory-domocratic community of the CARE hamlet. GRDBJB is a foster group or branch group that was formed with the aim of preservation and inheritance to the young generation of CARE which is oriented towards a non-commercialmanagement system and social orientation.
\end{abstract}




\section{PENDAHULUAN}

Grup Rapa'i Daboh Bungong Jeumpa Bantimoh (selanjutnya disingkat menjadi GRDBJB) merupakan kelompok rapa'i yang beranggota anak-anak dengan us ia rata-rata tujuh sampai belasan tahun. Grup tersebut didirikan oleh mas yarakat pengungsian Pasca Tsunami Aceh dari Pulau Aceh yang saat ini tinggal di pemukiman CARE, sejak tahun 2005. GRDBJB awalnya digagas oleh mas yarakat atas dorongan dan dukungan dari LSM pada masa rehabilitasi pasca bencana untuk kebutuhan pemulihan mental para korban atau trauma healing, khususnya diperuntukkan bagi anak-anak.

Reza Idria dalam artikelnya menyebutkan, bahwa, pada masa rehabilitasi dan rekonstruksi Aceh ( setelah tsunami), beratus-ratus lomba seni dibuat, dari lomba menulis, membaca puisi, festival teater, musik hingga lomba berhikayat untuk merayakan perdamaian. Meski canggung karena terasing dengan bentuk-bentuk kesenian yang diperlombakan oleh NGO-NGO yang datang membantu korban bencana, gairah ingin bangkit dari keterpurukan ditunjukan masyarakat dengan turut serta mengikuti lomba-lomba tersebut. Hal ini saya kira juga berkaitan dengan begitu besarnya jumlah bantuan yang beredar di Aceh pada masa rehabilitasi pasca tsunami (Idria, 2014).

Dukungan yang diberikan oleh LSM atau NGO bernama KKPA tersebut berupa peralatan untuk menunjang aktivitas latihan kesenian rapai daboh. Beberapa tahun kemudian, kelompok latihan tersebut berubah menjadi kelompok kesenian yang diperuntukkan untuk berbagai pertunjukan. Seiring dengan hal tersebut, s is tempengelolaan dibuat dengan tujuan untuk mengelola dua kelompok rapa'i daboh sekaligus: rapa'i daboh dewasa (Grup Rapa'i Daboh Bungong Jeumpa) dan rapai daboh anak-anak (Grup Rapa'iDaboh Bungong Jeumpa Bantimoh) di kawasan pengungsian Pasca Tsunami Aceh, CARE, Kota Jantho, Kabupaten Aceh Besar.

Rapa'i Daboh adalah kesenian rapa'i (rebana) yang dipadukan dengan atraksi pertunjukan debus. Rapa’i dan kes enian rapa'i daboh di Aceh biasanya dimainkan oleh beberapa orang laki-laki remaja dan dewasauntuk mengiringi pertunjukan debus. Permainan debus dimainkan oleh dua sampai empat orang untuk setiap pertunjukan rapa'i daboh. Kelompok-kelompok rapa'i daboh yang tersebar di beberapa daerah di Aceh pada umumnya beranggotakan orang laki-laki remaja dan dewasa sebagai pemain alat musik rapa'i maupun pemain debus.

Berbeda dengan sebagian kelompok rapa'i daboh yang ters ebar di wilayah Provinsi Aceh GRDBJB merupakan pengecualian dari kelompok rapa'i daboh di Aceh pada umumnya. GRDBJB sebagaimana disebutkan sebelumnya, merupakan kelompok rapa'i daboh anakanak. Anak-anak dalam hal ini menempati posisi sebagai pemain rapa'i pada saat pertunjukan rapa'i daboh. Sedangkan untuk pemain debus biasanya dimainkan oleh orang dewasa. Namun, tidak tertutup kemungkinan jika telah memenuhi syarat, anak-anak yang sudah baligh pun jugabisa menjadi pemain debus.

Hadirnya GRDBJB sebagai kelompok rapai anak-anak di tengah masyarakat pengungsian Pasca Tsunami, CARE, Kota Jantho, merefleksikan adanya sebuah sebuah bentuk kemampuan adaptasi dalammenghadapi berbagai situasi dalam sistem pengololaannya, salah satunya persoalan menghadapi ekonomi yang benbah di tengah mas yarakat y ang berpindah secara geografis. Sebagaimana yang dis ampaikan Lindsay dalam buku "Telisik Tradisi: Puspa Ragam Pengelolaan Seni", mengatakan bahwa, kesadaran tentang pentingnya kemampuan adaptasi dalam menghadapi situasi ekonomi yang berubah, dan dalam menanggani persaingan, sangatlah kentara. Grup-gnup mengembangkan pendekatan baru dalam pergelaran dan tatakelolanya; mis alnya, melalui promosi seperti seperti menawarkan diskon, menjual rekaman, atau membuka grup-asuh baru yang memperkenalkan gaya baru (Lindsay. 2006). Tentunya, sejalan dengan apa yang dis ampaikan Linds ay, bahwa hadirnya GRDBJB sebagai bentuk pengembangan kelompok kesenian dalam bentuk grup-asuh atau grup cabang dalam menghadapi situasi sosio-geografis dan ekonomi masyarakat yang berubah.

Kehidupan yang tidak sama pers is dengan kehidupan pada saat sebelum Tsunami Aceh di Pulau Aceh, menjadikan mas yarakat harus bertahan deng an kondisi ekonomi yang berbeda dengan sebelumnya. Kondisi sosio-geografis dan ekonomi yang berubah membuat mas yarakat Pulau Aceh yang telah menempati kawasan pemukiman pasca Tsunami Aceh, CARE, Kota Jantho, Kabaputen Aceh Besar, harus beradaptasi dengan lingkungan sosial dan geografis yang baru. Bebarapa dari masyarakat sanggup bertahan hingga saat ini. Namun sebagiannya telah kembali ke Pulau Aceh setelah menempati kawasan pemukiman baru yang disediakan pemerintah dengan jangka waktu hanya 
beberapa tahun. Bagi mas yarakatyang mas ih bertahan, tetap menjalankan kehidupan dengan berbagai cara. Salah s atu y ang menjadiday a tarik adalah, mas yarakat tersebut merevitalisasi beberapa bentuk kebudayaannya, salah satunya kes enian rapa'i daboh.

Kebudayaan dalam berbagai bentuk, tidak bisa dilepaskan dari aspek kehidupan sosial-relijius masyarakat Aceh. Kebudayaan menjadi kekuatan bagi mereka untuk bertahan dalamberbagai kondisi, seperti halnya persoalan konflik yang cukup panjang beberapa dekade lalu. Masyarakat Aceh memandang bahwa kesenian rapa'i juga diyakini memberikan kekuatan sosial yang dapat memberikan persatuan dan perdamaian. Dalam artian, rapa'i dalam perjalanan sejarahnya tidak hanya mengangkat moral sosial pendukungnya, tetapi juga menjadi pengikat dan pengerat jalinan sosial masyarakat (Ediwar, et.al. 2015).

Studi kasus pengelolaan dan penyajiannya menampilkan repres entasi tentang kekuatan daya hidup tatakelola pergelaran, yang diamati dalam sistem pengelolaan kelompok rapai anak-anak dengan nama Grup Rapa'i Daboh Bungong Jeumpa Bantimoh menjadi manarik dan relevan di tengah minimnya ketertarikan atas penelitian terhadap keragaman sistem dan gaya tatakelola kelompok kesenian tradisi di Indonesia.

Penelitian ini bertujuan untuk mengakomodasi dan mendokumentasi pengetahuan tradisional terkait bentuk tatakelola yang diterapkan dalam kelompok GRDBJB sebagai grup-asuh yang hidup di tengah masyarakat yang menghadapi sosio-geografis yang berubah di kawas an pengungsian pasca Tsunami Aceh, CARE, Kota Jantho, Kabupaten Aceh Besar. Berangkat dari penjabaran di atas, maka penelitian ini merumuskan dua permasalahan, yaitu: Pertama, bagaimana bentuk tatakelola GRDBJB di kawasan pengungsian pasca Tsunami Aceh, CARE, Kota Jantho, Kabupaten Aceh Besar; Kedua, bagaimana strategi pengelolaan GRDBJB dalam menghadapi sosio-geografis dan ekonomi yang berubah. Maka, penelitian ini nantinya akan mengungkap bentuk dan sistem tatakelola GRDBJB, serta mendeskripsikan aspek-aspek lain yang melingkupi fokus kajian ini, di antaranya: bentuk pengelolaan, sis tem kepemimpinan, dan sis temkepemilikan kelompok kes enian tradisional dalam GRDBJB.

\section{KAJIAN TEORI}

\section{Sistem Kelembagaan Seni}

Gorga : Jurnal Seni Rupa

Volume 09 Nomor 02 Juli-Desember 2020

p-ISSN: 2301-5942 | e-ISSN: 2580-2380

Sesuatu y ang dilembag akan biasan ya mempunyai dasar dan alasan tertentu baik yang berupa konservasi, pembinaan, pengembangan dan atau alasan lainnya. Apabila seni pertunjukan sebagai cabang kesenian dilembagakan berarti minimal mengandung maksud, pembinaan dan pengembangan (Jazuli. 2014).

Pembinaan dapat dimengerti sebagai upaya yang meliputi pemeliharaan, penyelamatan, pelestarian, pengelolaan dan termasuk di dalammny a adalah upaya memberikan bimbingan, pengarahan, penggalian, pencatatan, dan peningkatan kualitas. Pengembangan mengandung dua pengertian, yaitu: 1) Pengembangan dalam arti pengolahan berdasarkan unsur-unsur yang telah ada, kemudian ditingkatkan sesuai tuntutan situasi tanpa mengurangi atau menghilangkan nilai yang ada sebelumnya, 2) Pengembangan dalam arti penyebarluasan agar dapat dapat dinikmati dan diresapi khalayak luas. Upaya pembinaan dan pengembangan akan senantiasa diselaraskan dengan alam pikiran, pandangan hidup, tingkat kehidupan masyarakat bes ertakondisi lingkungannya (Setyawati dalam Jazuli. 2014).

Pelembagaan kesenian, termasuk seni pertunjukan tradisional di Indonesia, dilakoni oleh pemerintah dan swasta. Pihak pemerintah biasanya diselenggarakan melalui institusi, sedangkan pihak s wasta dengan cara mendirikan sebuah perkumpulan atau grup kesenian baik secara kolektif maupun perorangan (Jazuli. 2014).

Pihak swasta yang biasa melembagakan pertunjukan biasanya terdiri dari, pimpinan agama atau pimpinan adat, dan seniman yang berhubungan langsung dengan kesenian tersebut. Bagi seniman, tentu mempunyai misi sendiri seperti wahana ekspresi dan komunikasi tentang pengalaman yang barangkali sangat berguna dan bermakna bagi mas yarakat penontonnya(Jazuli. 2014).

Berdirinya suatu kelompok atau grup seni pertunjukan tradisional tidak terlepas dari dua alasan tersebut di atas, yaitu: pembinaan dan pengemban gan. Tentunyadi balik alasan tersebut, tersirat beberapa tujuan lain, seperti tujuan komersil dan non-komersil (Jazuli. 2014).

Tujuan komersil maksudnya adalah untuk memperoleh keuntungan finansial dan sering menjadi sandaran hidup pelakunya; sedangkan tujuan non-komersil lebih menekankan sifat sosial dan pengembangan kebudayaan, seperti untuk sarana pendidikan, kelangsungan hidup kesenian yang bersangkutan, dan media komunikasi (Jazuli. 2014). 


\section{Sistem Pengelolaan}

Berdas arkan pengelolaan pertunjukan bis a dibedakan menjadi dua, yaitu secara amatir dan profesional. Profesional sering diartikan melaksanakan suatu kegiatan untuk memperoleh uang sebagai mata pencaharian, dan juga melakukan suatu kegiatan yang dilandasi oleh keahlian yang tinggi. Amatir sering diartikan melakukan suatu kegiatan berdasarkan kesenang an (hobi), tidak semata-mata untuk mencari uang, dan tidak menuntut keahlian tinggi dalam melakukan pekerjaan (Jazuli. 2014). Dua pengertian tersebut sering dikaitakn dengan masalah kualitas pertunjukan, terutama di Barat (Eropa dan Amerika).

Dua orientasi tersebut di atas, tampaknya tidak selalu tepat bila diterapkan di Indonesia, dikarenakan latar belakang maupun kondisi sosial dan budaya yang berbeda. Di Indonesia, tidak jarang bahwa kegiatan yang sifatnya untuk kesenangan dilakukan oleh orangorang atau seniman y ang memiliki keahlian khusus dan kredibilitas tinggi, bahkan kualitasnya cukup baik. Oleh karena itu, pengertian profesional dan amatir lebih layak bila dikaitakan dengan landasan kerja, etos kerja dan cara kerja. Dengan demikian profesional dapat dimengerti sebagai suatu aktivitas usaha y ang dilandasi oleh sikap dan perilaku yang efisien, efektif, rasional pragmatis, dan produktif (Jazuli. 2014).

Profesional mempersyaratkan adanya kemampuan tinggi (khusus), rencana kerja yang matang, motivasi dan keinginan untuk bekerja keras, ulet, penuh kreativitas dan dedikasi. Sasaran profesional adalah untuk memperolah prestise, keuntungan finansial, mencapai kualitas produk yang tinggi, dan boleh jadi dapat sebagai s andaran hidup. Sebaliknya, amatir dapat dimengerti sebagai kegiatan yang dilandasi oleh kesenang an, bukan sebag ai sumber pendapatan utama, kurang berorientasi pada keuntungan finansial, dan perencanaan dan cara kerja relatif kurang serius, kurang matang, dan yang penting bisa berjalan lancar (Jazuli. 2014).

Mengutip yang disampaikan Lindsay di muka, yang mengatakan bahwa, kesadaran tentang pentingnya kemampuan adaptasi dalam menghadapi situasi ekonomi yang berubah, dan dalam menanggani persaingan, sangatlah kentara. Grup-grup mengembangkan pendekatan baru dalam pergelaran dan tatakelolanya; misalnya, melalui promosi seperti seperti menawarkan diskon, menjual rekaman, atau membuka grup-asuh baru yang memperkenalkan gaya baru (Lindsay. 2006: 13). Tentunya, sejalan dengan apa yang dis ampaikan Lindsay, bahwa hadirnya GRDBJB sebagai bentuk pengembangan kelompok kesenian
Gorga : Jurnal Seni Rupa

Volume 09 Nomor 02 Juli-Desember 2020

p-ISSN: $2301-5942$ | e-ISSN: 2580-2380

dalam bentuk grup-asuh atau grup cabang dalam menghadapi situasi sosio-geografis dan ekonomi masyarakat yang berubah.

\section{METODE PENELITIAN}

Metode penelitian pada umumnya terbagi kepada dua metode yang lazim digunakan yaitu metode penelitian kualitatif dan metode penelitian kuantitatif. Dari dua jenis metode penelitian ini nantinya menggunakan metode penelitian kualitatif. "Penelitian kualitatif didefinis ikan oleh Bogdan dan Taylor sebagai prosedur yang menghasilkan data deskriptif berupa kata-kata tertulis atau lis an dari orang-orang dan perilaku yang dapat diamati (Bogdan dan Taylor dalam Moleong. 1995). Untuk mendukung metode penelitian kualitatif sebagai metode penelitian y ang telah dipilih, maka juga dilakukan beberapa tahapan penelitian. Adapun beberapa tahapan sesuai dengan dikemukakan oleh Bogdan. Ia meny ajikan tiga tahapan dalammelakukan proses penelitian kualitatif, yaitu:(1). Pralapangan; (2). Kegiatan lapangan; (3). Dan analis is intensif (Bogdan dan Taylor dalam Moleong. 1995). Untuk itu, dalam proses penelitian ini telah dilakukan beberapa langkah sebagai bagian dari beberapa tahap penelitian sesuai dengan yang dinyatakan Bogdan.

Tahap pra lapangan ini berbentuk studi pustaka yang menjadi langkah awal dalam melakukan suatu penelitian pada tahapini. Studi pustaka sangat berguna untuk mengetahui apakah objek serta permasalahan yang akan diteliti ini sebelumnya sudah diteliti sebelumnya. Tahapan ini akan diawali dengan mengumpulkan referensi-referensi berupa buku, majalah, jurnal dan sumber tertulis lainnya guna memperkuat penelitian tersebut yang nantinya akan dituangkan ke dalam bentuk tulisan. Di samping itu juga menjadi pedoman dan pendukung dalam melaksanakan penelitian tentang "Sistem Tatakelola Grup Rapa'i Daboh Bungong Jeumpa Bantimoh di Kawasan Pengungsian Pasca Tsunami Aceh, CARE, Kota Jantho".

Langkah selanjutnyaadalah tahap kerja lapangan untuk mengumpulkan data yang akan dianalisis menjadi sebuah bentuk laporan. Dengan melakukan studi lapangan yaitu pengumpulan data-data dengan cara melakukan observasi, wawancara serta pendokumentasian yang menggunakan alat dokumentasi seperti kamera foto, kamera vidio dan alat perekam berupa handphone.

Dalam tahap kerja lapangan atau diistilahkan dengan studi lapangan ini ditempuh melalui beberapa tahaptahap sebagai berikut: 
Terkait dengan pentingnya langkah observasi (pengamatan) dalam setiap penelitian. Penulis dalam hal ini akan mengamati secara langsung aktivitas pra hingga pasca pertunjukan GRDBJB selama proses penelitian ini berlangsung nantinya. Gunanya sebagai pendukung terhadap data yang diperoleh dalam studi pustaka pada tahap pra lapangan, sekaligus untuk meminimalis ir keraguan ag ar tidak terjadinya bias data yang diperoleh sebelum penelitian lewat studi pustaka yang dilakukan.

Proses dalam tahap wawancara akan dilakukan dalam bentuk tanya jawab antara penulis dan informan, dalam hal ini bersama Hamindan sebagai Ketua dan Zulkarnaini selaku sekretaris GRDBJB. Wawancara berkaitan langsung dengan objek dan fokus penelitian yang diteliti. Narasumber yang penulis temui adalah orang-orang dari unsur pengurus atau pengelola GRDBB serta pemain dari kelompok kesenian tersebut, dengan tujuan agar penulis mendapatkan data-data yang akurat tentang objek penelitian ini nantinya.

Proses pendokumentasian sangat penting guna membantu melengkapi data-data sebagai penunjang suatu penelitian dalam tahapan lanjutan analis is dan pengolahan data yang didapat di lapangan nantinya. Proses pendokumentasian mengunakan instrumen penelitian. Tahapan ini dilakukan dengan memanfaatkan kamera foto, kamera vidio, dan alat perekam audio berupa handphone.

Setelah mendapatkan data-data tentang objek yang akan diteliti melalui narasumber yang telah ditemui selama proses penelitian tentang model tatakelola GRDBJB di kawasan pengungsian Pasca Tsunami Aceh, CARE, di Kota Jantho berlangsung, maupun dari sumber-sumber lain seperti dari jurnal, laporan penelitian, buku, dan skripsi. Selanjutnya data-data ters ebut akan dipilih dan dilakukan penyis ihan untuk kemudian dianalisis. Data-data yang dianalisis kemudian disusun menjadi s ebuah laporan penelitian.

\section{HASIL DAN PEMBAHASAN}

\section{Hasil}

Berdasarkan hasil pengamatan langsung serta wawancara yang dilakukan sebagai bagian dari penelitian ini, maka dapat dilihat bahwa, sistem pengelolaan Grup Rapa'i Daboh Bungong Jeumpa Bantimoh (GRDBJB) didas ari oleh sistempengelolaan semi-profesional berbasis kolektif masyarakat dusun CARE. Kelompok rapa'i anak-anak yang merupakan bentukan dari Grup Rapa'i Daboh Bungong Jeumpa (GRDBJ) ini, dibentuk dengan tujuan pelestarian dan pewarisan kepada generasi muda dusun CARE yang
Gorga : Jurnal Seni Rupa

Volume 09 Nomor 02 Juli-Desember 2020

p-ISSN: 2301-5942 | e-ISSN: 2580-2380

berorientasi pada sis tempen gelolaan non-komers il dan orientasi s osial.

Tujuan non-komersil lebih menekankan sifat sosial dan pengembangan kebudayaan, seperti untuk sarana pendidikan, kelangsungan hidup kesenian yang bersangkutan, dan media komunikasi budaya kepada mas yarakat luas terhadap kesenian masyarakat dusun CARE.

Sistem pelembagaannya mengandung dua alasan, sejalan dengan pendapat Jazuli sebelumnya: Pertama, pembinaan sebagai bentuk upaya yang meliputi pemeliharaan, penyelamatan, pelestarian, pengelolaan dan termasuk di dalammnya adalah upay a memberikan bimbingan, pengarahan, penggalian, pencatatan, dan peningkatan kualitas dari kalangan orang tua yang merupakan seniman pelaku kesenian rapa'i yang terg abung dalam GRDBJ. Kedua, Pengembangan, yang mengandung dua pengertian, yaitu: 1) Pengembangan dalam arti pengolahan berdasarkan unsur-unsur yang telah ada, kemudian ditingkatkan sesuai tuntutan situasi tanpa mengurangi atau menghilangkan nilai yang ada sebelumnya, 2) Pengembangan dalam arti penyebarluasan agar dapat dapat dinikmati dan diresapi khalayak luas.

Pendirian kelompok atau grup seni pertunjukan rapa'i daboh dengan nama Grup Rapai Daboh Bungong Jeumpa Bantimoh (GRDBJB) oleh seniman-s eniman rapa'i yang merupakan bagian dari masyarakat dusun CARE, menjadi indikator adanya sebuah usaha pelembagaan seni pertunjukan dengan alasan pembinaan serta pengembangan, yang di dalamnya terdapat semangat konservasi untuk kesenian rapa'i daboh milik masyarakat Pulau Aceh yang telah menetap di kawasan pemukiman Pasca Tsunami, dusun CARE, Kota Jantho.

Pelembagaan seni yang dilakukan oleh pengurus GRDBJ dengan membentuk GRDBJB merupakan sebuah tujuan pembinaan y ang didasari oleh semangat dan upaya pemeliharaan, pelestarian, pengelolaan melalui sebuah kelompok baru sebagai grup asuh, yang dibekali melalui pembimbingan, pengarahan, dan peningkatan kualitas pertunjukan kepada generasi muda dusun CAREyang menjadi anggota atau pemain dalam GRBJB.

Peran seniman rapa'i daboh sebagai pihak swasta, sangat signifikaan dalam membentuk dan mengunusi tatakelola GRDBJB. Tujuannya adalah tidak lain untuk kelangsungan dan keberlanjutan kehidupan kesenian rapa'i daboh di dusun CARE di tangan generasi 


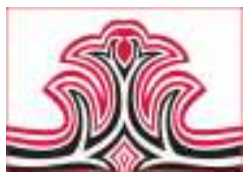

selanjutnya. Dilembagakannya pertunjukan rapa'i daboh yang diisi oleh formasi anak-anak sebagai pemain, juga menjadi semacam bentuk kaderisasi di dalam tubuh kesenian rapa'i daboh milik masyarakat pengungsian pasca tsunami Aceh, CARE, Kota Jantho.

Semangat pelembangaan seni oleh pengurus dan seniman yang tergabung dalam GRDBJ terhadap GRDBJB diikuti dengan semangat pengelolaan organis asi kesenian tersebut dengan manajemen atau tatakelola sederhana dan bersifat setengah moderen. Hal ini ditandai dengan adanya upaya pengelolaan dalam bentuk pendirian grup baru, sistem pengurusan, sis temperekrutan, pengelolaan keunag an, serta s trategi pertunjukan.

\section{Pembahas an}

Jenis seni pertunjukan dari budaya peninggalan masa lampau tampaknya masih ada, baik yang berorientasi sosial maupun komersil. Seni pertunjukan yang berorientasi sosial, seperti seni pertunjukan yang berhubungan denga upacara keagamaan, upacara adat, sarana komunikasi antar warga (kekerabatan), dan sebagai hiburan (Jazuli. 2014)

Lembaga seni pertunjukan yang sampai sekarang masih dipelihara dengan baik oleh warga bisa disaksikan di desa-desa y ang mas ih menyelenggarakan tradisi-tradisi agraris. Berkaitan dengan pertunjukan yang diselenggarakan setelah panen, sebagai sarana hiburan dan mengisi waktu luang. Termasuk salah satunya, kesenian rapa'i daboh yang dimainkan oleh Grup Rapa’i Daboh Bungong Jeumpa Bantimoh di dusun CARE, Kota Jantho.

Dalam melihat fenomena sistem tatakelola GRDBJB, penelitian ini memilih enam topik bahasan: Pembentukan Grup Rapa'i Daboh Bungong Bantimoh; Sistem Kepengurusan Grup Rapa'i Daboh Bungong Bantimoh; Sistem Perekrutan Grup Rapa'i Daboh Bungong Jeumpa Bantimoh; Strategi Pertunjukan/ Promosi/ Pemesanan; Pengelolaan Keuangan Grup Rapa'iBungong Bantimoh; dan Persiapan Pertunjukan. Adapun pembahasannya sebagai berikut:

\section{1).Pembentukan Grup Rapa'I Daboh Bungong Bantimoh}

Grup Rapa'i Daboh Bungong Jeumpa Bantimoh (GRDBJB) adalah sebuah kelompok kesenian yang hidup dan berkembang di tengah kawasan pengungsian Pasca Tsunami Aceh, CARE, di Kota Jantho. Dibentuk atas gagasan dan keinginan masyarakat CARE dan pengurus inti dari Grup Rapa'i Daboh Bungong Jeumpa (GRDBJ) yang lebih dulu terbentuk sejak
Gorga : Jurnal Seni Rupa

Volume 09 Nomor 02 Juli-Desember 2020

p-ISSN: 2301-5942 | e-ISSN: 2580-2380

tahun 2013. Sebelumnya, yang menjadi cikal bakal dan terbentuknya GRDBJ, pada mulanya bernama Grup Rapa'i Daboh Bungong Sitangkee (GRDBS), yang telah digagas pada saat bersamaan saat masyarakat Pulau Aceh mulai menempati kawasan pemukiman Pasca Tsunami, CARE, Kota Jantho.

Nama "Bungong Jeumpa Bantimoh" diambil dari bahasa Aceh yang berarti "Bunga Jeumpa yang baru tumbuh". Sebuah tunas yang akan menjadi bunga. Selain itu, nama tersebut dipakai sebagai penanda bahwa kelompok rapa'i daboh anak-anak tersebut merupakan bagian maupun cabang dari Grup Rapa'i Daboh Bungong Jeumpa yang juga merupakan nama kolektif dari kelompok kes enian tersebut. Penambahan kata "bantimoh" atau "baru tumbuh" pada nama Bungong Jeumpa yang dipakai GRDBJB memiliki maksud bahwa, kelompok kes enian ini sebagai "tunas baru" yang akan menjadi generasi selanjutnya dari GRDBJ, yang diharapkan akan meneruskan pewarisan untuk tujuan peles tarian kesenian rapa'i daboh milik mas yarakat Pulau Aceh yang tinggal di dusun CARE.

Sebagaimana yang telah diketahui, GRDBJB adalah grup kesenian rapa'i yang menyertakan permainan debus. Atraksi debus terintegrasi pada hampir setiap pertunjukannya, kecuali ada permintaan khusus dan yang punya hajat untuk tidak menampilkan atraksi debus, dan hanya menampilkan pertunjukan rapa'i. Meskipun para anggota pemainnya adalah anak-anak, untuk penampilan debus, bias anya dipraktikkan oleh orang dewasa yang merupakan anggota kelompok GRDBJ.

Setidaknya ada belasan jenis kesenian rapa'i di Aceh. dengan karekteristik dan gaya penyajian maupun pertunjukkannya yang khas. Mengutip H. M. Amin yang mengatakan: "Pada suatu ketika tanggal 8-10/ Januari 2014 dalam rangka dialog seni dengan judul pemetaan tari tradisi Aceh di enam wilayah yang terdiri: Aceh Timur, Aceh Utara, Aceh Tamieng, Birueun, Subulussalam, Aceh Besar, menyepakati tentang asal mula rapa'i yaitu rapa'i uroh, yang selanjutnya melahirkan rapa'i zikir, rapa'i saman, rapa'i geleng, rapa'i hapit, rapa'i lagee, rapa'i anggok, rapa'i siddik/ sedat, rapa'ibruek/ tempurung dan rapa'i ratoh/ ratab. Selanjutnya dari rapa'i tuha dan rapa'i daboh lahir rapa'i pulot, rapa'i koay/nazar, rapa'i duek/ uroh duduk dan s ebagianya(H.M. Amin dalamEdiwar, et.al. 2014).

GRDBJB merupakan jenis kesenian rapa'i dan debus. Kes enian yang disajikan GRDBJB memiliki perbedaan dalam konsep penyajian dan pertujukannya dengan 


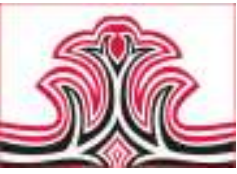

jenis rapa'i aceh lainnya, seperti yang disebutkan di atas. Rapa'i daboh (debus), dimainkan dengan posisi duduk dan pemain debus dalam posisi berdiri. Rapa'i daboh (rapa'i debus) merupakan pertunjukan permainan musik rapa'i yang disertai dengan atraksi debus (pertunjukan y ang menghujamkan senjata tajam ke begian tubuh tertentu dari pemain debus) sebagaimana atraksi debus y ang ada di daerah lainnya, seperti, Sumatera Barat dan Banten (Ediwar, et.al. 2014).

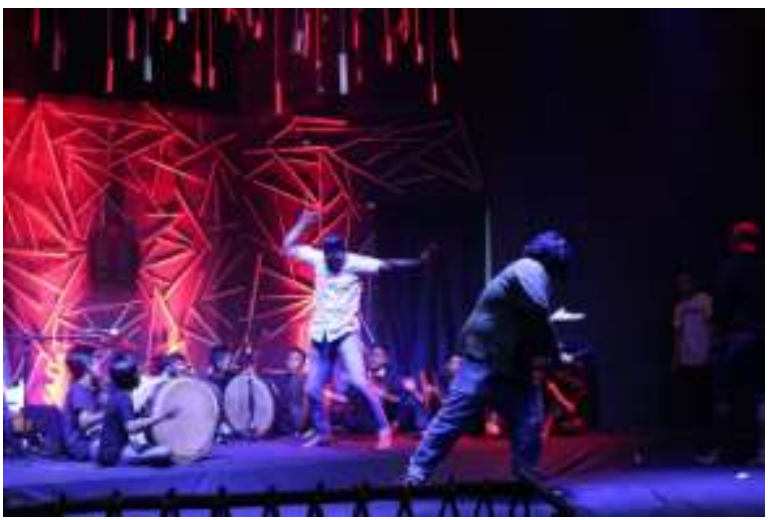

Gambar 1. Pertunjukan Grup Rapa'i Daboh Bungong Jeumpa Bantimoh dengan Menyertakan Atraksi Debus, pada Iven Urlaka Prodi Seni Karawitan, di Kampus ISBI Aceh.

(Sumber: Rika Wirandi, 2018)

Sebagai sebuah kelompok seni tradisional yang bernuansa Islam dengan klasifikasi s eni akrobatik yang mempertontonkan atraksi kekebalan tubuh dari hujaman senjata tajam. Atraksi ini dikenal umum oleh masyarakat Indonesia dengan istilah debus atau pertunjukan debus. Pertunjukan-pertunjukan ini (meskipun pada tingkat yang terus berkurang dibanding sebelumnya) secara universal dipraktikkan selunuh Kepulauan Timur di bawah nama dabus, debus atau pertunjukan gedebus. Istilah ini berasal dari bahasa Arab dabbus, jarum besi, yang digunakan sebagai instrumen utama untuk melukai badan. Orang Aceh juga berbicara mengenai daboh (senjata) dan meudaboh (penggunaan senjata) atau lain menyebutkan pertunjukan rapa 'i (dari Rifa'i) is tilah yang digunakan untuk menunjukkan tamborin yang digunakan dalam pertunjukan ini dan dalam zikir-zikir lain (Hurgronje. 2020)."

GRDBJB dibentuk sebagai kelompok binaan atau gup asuh dari GRDBJ. Kelompok ini dihidupkan oleh masy arakat asli Pulau Aceh y ang ting gal di pemukiman CARE, Kota Jantho. GRDBJB dibentuk dengan cara mewariskan bakat permainan alat musik rapa'i dari anggota GRDBJ yang juga merupakan para orang tua dari anggota GRDBJB.
Gorga : Jurnal Seni Rupa

Volume 09 Nomor 02 Juli-Desember 2020

p-ISSN: 2301-5942 | e-ISSN: 2580-2380

GRDBJB pada saat ini telah berusia kurang lebih 3 tahun tahun. Terbentuknya GRDBJB, sebagaimana yang telah disampaikan di muka, diawali dengan pembentukan GRDBJ pada tahun 2013 sebagai kolempok kes enian rapa'i daboh yang pamainnya ratarata adalah laki-laki dewasa dan orang tua. GRDBJB ini mulanya dibentuk dengan tujuan agar anak-anak pada pemukiman CAREini tidak menghabiskan waktu untuk hal-hal yang tidak bermanfaat. Kemudian, tujuan lain dari didirikannya GRDBJB ini adalah agar tradisi rapa'i daboh yang merupakan kes enian tradisi Aceh ini agar tetap ada sebagai identitas masyarakat Pulau Aceh.

\section{2).Sistem Kepengurusan Grup Rapa'i Daboh Bungong Bantimoh}

Grup Rapa'i Daboh Bungong Jeumpa Bantimoh ini sama seperti Grup Rapa'i Bungong Jeumpa. Dipimpin oleh seorang ketua dan dibantu oleh sekretaris dan bendahara kelompok. Struktur organis asinya benupa struktur organisasi sederhana dan semi-moderen, yang umum dijumpai pada beberapa kesenian tradisional lainnya. Tidak ada sub-bagian ataupun divisi yang secara khusus mengurusi beberapa urusan tertentu, seperti, perlengkapan, artistik, rumah tangga, kesekretariatan, dan sebagainya. Bedanya, dalam sistem pengurusan kelompok rapa'i daboh GRDBJB maupun kes enian rapa'i daboh lainnya di daerah Aceh, dibantu oleh seorang penasehat dan seorang khalifah.

Peran khalifah dalam kelompok kesenian ini bersifat non-formal. Perannya lebih kepada pelindung, pemberi pertimbangan, sekaligus sebagai pawang untuk melindungi para pemain rapa'i ketika melakukan pertunjukan, terutama pada saat melakukan atraksi debus. Khalifah juga dapat berperan sebagai tabib, yang mengobati pemain debus yang terluka pada suatu insiden tertentu dalam pertunjukannya.

\section{"Pertunjukan ini(daboh) dilakukan di bawah} kepemimpinan seorang khalifah yang sebenarnya, yaitu, peng ganti spiritual pendiri tarekat, yang silsilah geneologis spiritualnya dihubungkan dengan Ahmad Rifa ' $i$, dan yangmendapat lisensi (ijazah) dari gurunya untuk melakukan latihan-latihan berbahaya semacamini (Hurgronje. 2020)."

Sistem kepengurusan GRDBJB ini masih diarahkan oleh orang tua yang merupakan anggota GRDBB. Kelompok ini diketuai oleh Hamidan yang juga merupakan ketua sekaligus sebagai s alah satu syeh/ceh dari Grup Rapa'i Bungong Jeumpa, dikarenakan GRDBJB merupakan grup asuh yang dibentuk dan dibina di bawah kepengurusan pengurus GRDBB. 
GRDBJB memiliki anggota tetap sebany ak 15 orang, 3 di antaranya menjadi pemain cadang an dalam sebuah pertunjukan rapa'i daboh (Wawancara dengan Zulkarnain, pada tanggal 14 September 2020, di CARE). Sama sepertiGRDBJ, GRDBJB juga memiliki 2 orang syeh/ceh, yakni Mutara dan Basir, yang berperan sebagai pemimpin dalam pertunjukan GRDBJ. Berbeda dengan anggota GRDBJ, anggota GRDBJB tidak terlibat dalam kepengurusan inti, dikarenakan masih anak-anak. Rata-rata mereka terlibat sebagai anggota sekaligus pemain rapa'i. Sedangkan pengurus inti GRDBJ juga merangkap menjadi anggota atau pemain rapa'i dan pemain debus.

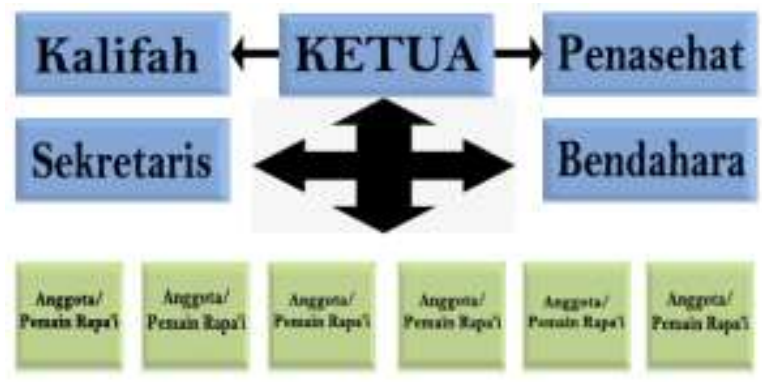

Gambar 2. Bagan Struktur Kepengurusan Grup Rapai Daboh Bungong Jeumpa Bantimoh (Sumber: Hamidan dan Zulkifli. 2020)

Pola kepemimpinan ketua dalam kepengurusan GRDBJB bersifat demokrasi. Pola pengelolaannya dilakukan secara kolektif-partisipatif-demokratis. Maksudnya, setiap urusan apapun yang terkait dengan internal kelompok, selalu dimusyawarahkan dengan seluruh anggota maupun pengurus. Persoalan bisa meliputi, mempertimbangkan undangan pertunjukan, persiapan pertunjukan, pergantian pemain rapa'i jika ada pemain inti yang berhalangan ikut dalam pertunjukan, pembagian honor, hingga pada persoalan kesalahpahaman yang terjadi antar anggota maupun pengurus.

\section{3). Sistem Perekrutan Grup Rapa'i Daboh Bungong Jeumpa Bantimoh}

Pada awalnya, perekrutan anggota Grup Rapa'i Bungong Jeumpa Bantimoh (GRDBJB) ini dilakukan secara atokrasi atau sis tem tunjuk langsung oleh ketua kelompok dari anggota Grup Rapa'i Bungong Jeumpa (GRDBJ). Dalam hal ini, hanya anggota keluarga saja yang bisa bergabung ke dalam kelompok GRDBJ. Akan tetapi seiring berjalannya waktu anggota GRDBJB sudah bisa direkrutdariberbagai pihak, tidak hanya keluarga anggota GRDBJ saja. Namun juga masyarakat sekitar dusun CARE, maupun di luar CARE. Hal ini mengingat salah satu tujuan dari dibentuk dan dibinanya grup asuh anak-anak rapa'i daboh ini sebagai sarana mengekspresikan diri,
Gorga : Jurnal Seni Rupa

Volume 09 Nomor 02 Juli-Desember 2020

p-ISSN: 2301-5942 | e-ISSN: 2580-2380

pendidikan dan penegenalan budaya dari usai dini, serta pewarisan secara estafet kepada ke negerasi muda dusun CARE. Tentunya, sebagai bentuk pelestanian kesenian tradisi yang khas dari Pulau Aceh.

Pola perekrutan yang dilakukan secara demokrasi diberlakukan setelah kepengurusan terbentuk secara resmi pada tahun 2013. Kepengurusan baru tersebut, sebagaimana yang telah dijelaskan sebelumnya, mengelola dua kelompok rapa'i daboh secara bers amaan. Proses perekrutan ju ga mempertimbangkan kemampuan anggota kelompok yang akan menjadi pemain dalam pertunjukan rapa'i dan pemain debus. Kemampuan dilihat dari penguasaan terhadap maten pertunjukan dan tingkatan kemampuan anggota agar tidak mengalami insiden dalam setiap pertunjukan, dikarenakan pertunjukan rapa'i daboh memiliki risiko yang cukup tinggi karena menampilkan atraksi akrobatik yang cukup ekstrim, sebagaimana atraksi pertunjukan debus pada umumnya.

GRDBJB paad saat ini beranggota anak-anak yang berumur kurang lebih 4 hingga 13 tahun. Setelah memasuki usia 13 tahun ke atas, biasanya anak anak yang tergabung dalam GRDBJB direkrut untuk bergabung dengan GRDBJ. Untuk pertunjukannya, anggota yang bermain hanya 12 orang dengan 3 orang sebagai cadangan. Pemain inti dipilih atas dasar kemampuan dalam memainkan rapa'i dan menguasai materi dan juga ked is pilinan dalam mengikuti latihan.

\section{4). Strategi Pertunjukan/ Promosi/ Pemesanan} GRDBJB adalah kelompok kesenian tradisional Aceh yang memiliki lingkungan khusus untuk wadah pertunjukannya. Sebagai sebuah kesenian tradisi yang cukup pupuler, GRDBJB hadir dalam beberapa seremonial yang bersifat adat maupun agama dalam masyarakat Aceh. Beberapa di antaranya, seperti, hajatan perkawinan, khitanan, aqiqah, kenduri selamatan, dan sebagainya. Selain itu, GRDBJB juga kerap mengisi undangan pertunjukan untuk iven-iven yang bersifat sekuler atau populer, seperti iven kesenian lokal-dari tingkat kecamatan hinggatinggkat provinsi Aceh, di antaranya Pekan Kebudayaan Aceh; acara penyambutan tamu pemerintahan dan ulang tahun kota; hajatan kampanye partai politik; dan iven-iven musik tingkat kampus, sebagai tamu undangan (Wawancara dengan Hamidan, tanggal 14 September 2020, di CARE). 


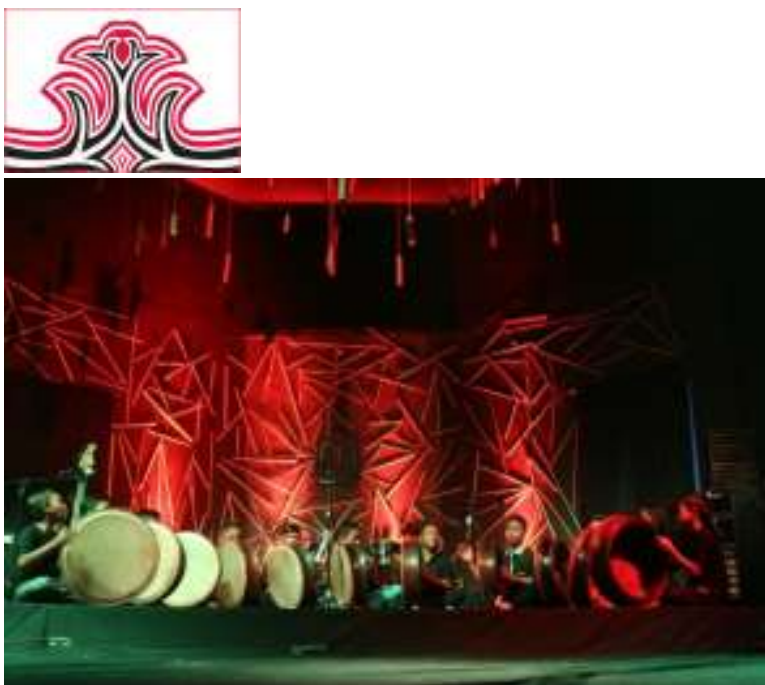

Gambar 3. Pertunjukan Grup Rapa’i Daboh Bungong Jeumpa Bantimoh di Kampus ISBI Aceh

(Sumber: Syahrul Qadri, 2018)

Sebagai kelompok kesenian tradisi yang berorientasi pada sosial dan non-komersil, GRDBJB tidak mematok uang tarif jemputan untuk sekali pertunjukan. Begitupun patokan honor bagi grup untuk setiap undangan pertunjukan pada iven-iven tertentu. Dikarenakan GRDBJB dibentuk sebagai grup asuhatau grup cabang dengan alasan pembinaan dan pengembangan, dengan tujuan non-komersil, dalam artian, lebih mengedepankan fungsi sosial kesenian tersebut. Sebagaimana yang disebutkan sebelumnya, bahwa ada dua alasan berdirinya sebuah grup pertunjukan, terutama y ang digagas oleh pihak s wasta, dalam hal ini seniman atau pelaku kesenian rapa'i daboh, dusun CARE. Selain alasan pembinaan dan pengembangan - juga ada tujuan lain: komersil dan non-komesil, maupun tujuan sosial.

Tujuan komersil maksudnyaadalah untuk memperoleh keuntungan finansial dan sering menjadi sandaran hidup pelakunya; sedangankan tujuan non-komersil lebih menekankan sifat sosial dan pengembangan kebudayaan, seperti untuk sarana pendidikan, pengekspresian diri, kelangsungan hidup kesenian yang bersangkutan, dan media komunikasi (Jazuli. 2014).

Strategi yang dilakukan sekaligus upaya untuk mempromosikan GRDBJB saat ini masih secara tradisoinal melalui pertunjukan dari pangung ke pagung, dari relasi ke relasi. Dahulunya pertunjukan rapa'i daboh hanya dilakukan pada saat acara-acara besar Islam. Tujuan dari strategi tersebut agar menjadikan kelompok ini semakin dikenal di masy arakat dan pemerintah daerah. Sehingga GRDBJB sering diundangan pada beberapa acara dan menjadi perwakilan kesenian dari Kabupaten Aceh Besar pada acara Pekan Raya Aceh pada tahaun 2018-2019. Hal ini menjadi prestasi sekaligus promosi yang baik terhadap GRDBJB. Selain menerima undangan pertunjukan dari
Gorga : Jurnal Seni Rupa

Volume 09 Nomor 02 Juli-Desember 2020 p-ISSN: 2301-5942 | e-ISSN: 2580-2380

berbagai acara GRDBJB jug a tidak menatap tarif untuk pertunjukannya, sehingga sanggar ini mudah untuk diterima dan diundang mas yarakat tanpa memandang ekonomi kelas bawah, menengah hingga atas. Hal ini menjadi daya tarik bagi masyarakat Aceh sehingga terkesan akrab dan kekeluaragan.

\section{5). Pengelolaan Keuangan Grup Rapa'i Bungong Bantimoh}

Setiap setelah pertunjukan GRDBJB, uang honor pertunjukan akan dibagi rata pada setiap anggota. Hal ini bertujuan sebagai penyemangat agar menjadi motivasi bagi anak-anak sangg ar agar lebih aktif lagi dalam kegiatan latihan. Dengan hal ters ebut, GRDBJB dapat mengelola keuangan dengan memiliki dana simpanan atau dana kas untuk pengelolaan yang akan digunakan untuk kegiatan latihan dan keperluan sanggar lainnya. Namun uang kas y ang didapat bukan lah dari honor pertunjukan yang dilakukan oleh anakanak GRDBJB, melainkan juga dari pertunjukan orang dewasa yang pembagian tarif pertunjukan hanya digunakan untuk transportasi dan uang konsumsi, sisanyanya disimpan untuk kas kelompok untuk kepentingan bersama.

Selain uang pemasukan dari honor pertunjukan dai beberapa undangan, uang kas GRDBJB biasanya diperoleh dari sumbangan masyarakat dusun CARE. Sumbangan ini, selain dalam bentuk uang, juga dapat dalambentukbahan konsumsi latihan dan pertunjukan. Selain itu, sumbangan yang didapat dari mas yarakat, adalah sisa dana daribiaya perlombangan rapa'i daboh antar kampung, atau bias adisebut betungang - sebagai bentuk pesta raky at atau pesta kampung sehabis panen. Kegiatan pergelaran ini memang tidak selalu dilakukan, karena butuh biaya yang besar untuk penyelenggaraan. Selain mempertimbangkan sehabis panen juga ada pertimbangan lain, termasuk kondisi ekonomi yang tidak stabil yang dirasakan mas yarakat selama hidup di kawasan pengunsgsian Pasca Tsunami. Bagi masyarakat dusun CARE, untuk menghelat peristiwa betunang, selain momentum panen hasil sawah dan ladang, juga tergantung pada kesediaan uang. Sejalan dengan yang disampaikan Lindsay, bahwa, adanya uang, dipadu dengan waktu beris tirahat sehabis panen, menciptakan pergelaran kesenian (Lindsay. 2006).

Kegiatan betunang rapa'i, biasanya diadakan setahun sekali secara bergiliran antar kampung. Masyarakat dusun CAREmengundang kelompok rapa'i daboh dari Pulau Aceh, dan begitupun sebaliknya. Untuk menyelenggarakan helat kampung yang diisi dengan kegiatan "adu" rapa'i daboh ini, masyarakat secara 


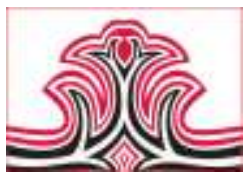

kolektif mengeluarkan iuran untuk pendanaan penyelengaraan tersebut.

Selain itu, pemasukan GRDBJB melalui GRDBJ berupa perlengkapan pertunjukan, seperti kostum pemain dan alat musik rapa'i. Sejauh ini, sumbangan beberapa set kostum pemain untuk pertunjukan diberikan oleh salah satu partai politik pada masa kampanye beberapa tahun lalu. Di sisi lain, pemerintah dalam hal ini dinas terkait, sebagaimana yang diutarakan ketua GRDBJ, belum pernah memberikan dana bantuan kesenian maupun fasilitas penunjuang kelompok kesenian kepada GRDBJ maupun GRDBJB, hanya saja baru sebatas pendataan yang merupakan kebutuhan program pendataan kelompok kesenian di dearah terkait. Adapun fasilitas tambahan, seperti pengadaan alat musik rapa'i tambahan, dibeli melalui sumbangan dari pengurus dan dana kas kelompok.

\section{6). Persiapan Pertunjukan}

GRDBJB memiliki jadal latihan rutin setiap minggu. Jadwal latihan dilakukan secara bergantian dengan GRDBB, dengan mengambil salah satu hari dalam satu minggu. Jadwal GRDBJB dilakukan pada hari Sabtu malam setelah waktu shalat isya. Sedangkan jadwal latihan GRDBJ pada hari Minggu malam. Pemilihan hari untuk jadwal latihan GRDBJB mempertimbangan hari libur sekolah, karena rata-rata pemainnya masih duduk di bangku sekolah dasar dan menengah. Jad wal latihan akan diperbanyak sebelum undangan pertunjukan. Namun, selama pandemi Covid-19, kelompok ini sangat jarang melakukan aktivitas latihan, dikarenakan tidak adanya undangan untuk melakukan pertunjukan, baik untuk kebutuhan hajatan, maupun iven seni budaya.

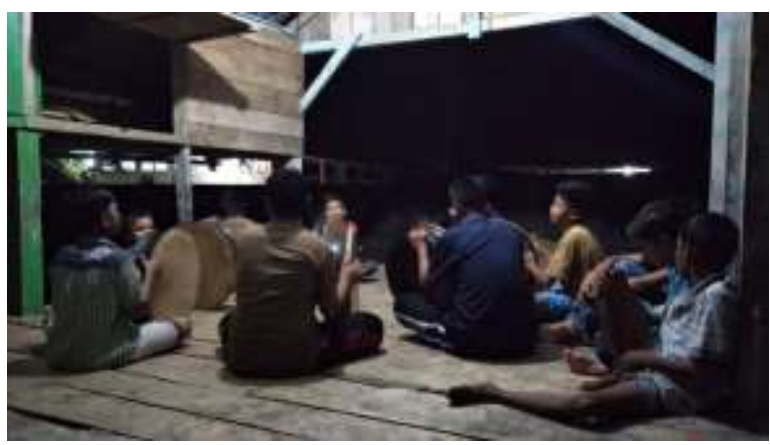

Gambar 4. Suasana Latihan Grup Rapa'i Daboh Bungong Jeumpa Bantimoh di Bale Dusun CARE

(Sumber: Rika Wirandi. 2020)

Proses latihan dilakukan di sebuah tempat yang disebut bale - semacama pendopo sederhana yang terbuat dari kayu. Bale tempat proses latihan GRDBJB terletak di tengah-tengah perkampungan, yang merupakan tempat
Gorga : Jurnal Seni Rupa

Volume 09 Nomor 02 Juli-Desember 2020 p-ISSN: 2301-5942 | e-ISSN: 2580-2380

pusat kesamaian warga. Tempat yang dibangun sejak awal-awal dibentuknya Grup Rapa'i Daboh Bungong Sitangkee iniberukuran: panjang sekitar lebih kurang 5 meter, lebar 3 meter, dan tinggi 4 meter.

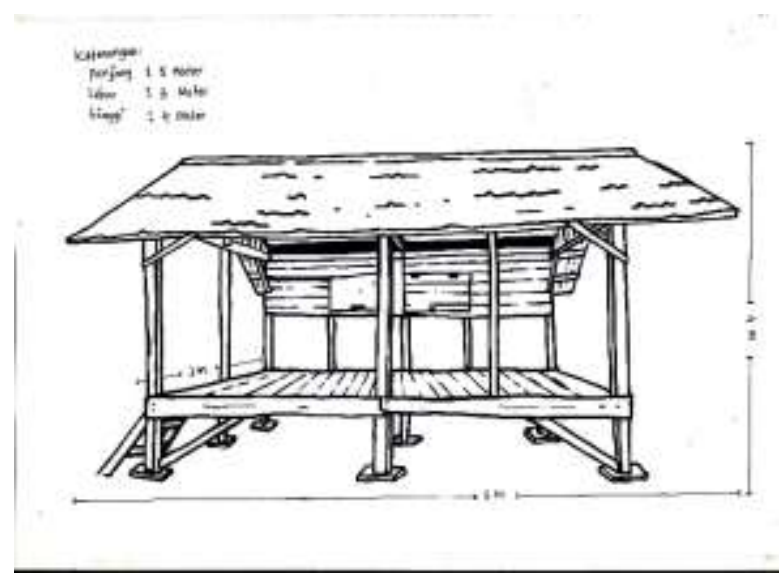

Gambar 5. Bale Latihan Grup Rapa'i Daboh Bungong Jeumpa di Dusun CARE

(Sketsa: Sabarudin. 2020)

Alat musik yang digunakan oleh anak-anak GRDBJB adalah rapa'i ring 14 dan ring 17 (Wawancara dengan Zulkarnain, pada tanggal 14 September 2020, di CARE). Kelompok ini memiliki rapa'i ukuran ring 14 sebanyak 12 buah dan rapai ukuran ring 17 sebanyak 12 buah. Ada beberapa jenis ukuran rapa'i yang digunakan pada beberapa jenis kesenian rapa'idi Aceh. Istilah "ring" digunakan untuk menandakan besar dan kecilnya ukuran rapa'i. Rapa'i yang umum dipakai adalah rapa'idengan ring 14 , ring 17 , ring 18 , dan ring 20. Alat musik rapa'i yang digunakan untuk pertunjukan rapa'i daboh Alat musik yang digunakan oleh anak-anak GRDBJB adalah rapa'iring 17 dengan klasifikasi ukuran sedang besar dan sedang. Untuk ukuran sedang besar dengan ukuran $50 \mathrm{~cm}$, dengan diameter $12 \mathrm{~cm}$. Ukuran sedang, dengan ukuran $48 \mathrm{~cm}$, dengan diameter $12 \mathrm{~cm}$ (Ediwar, et. al. 2014). 

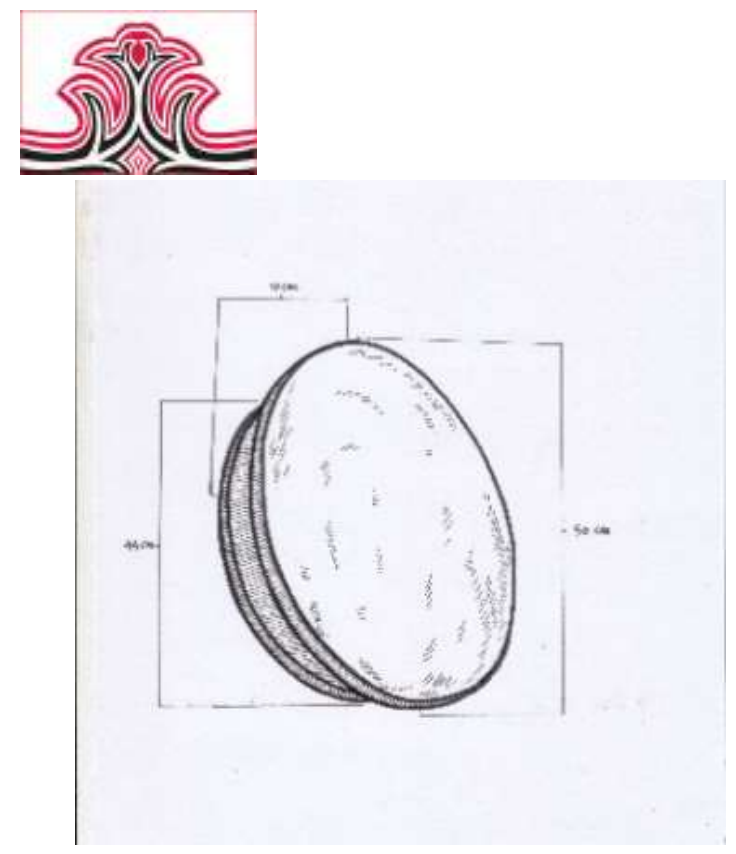

Gambar 6. Ukuran Alat Musik Rapa'i yang Digunakan untuk Latihan Grup Rapa'i Daboh Bungong Jeumpa Bantimoh (Sumber: Sabarudin. 2020)

Kostum yang digunakan pada saat pertunjukan GRDBJB menyesuaikan kostumnya dengan GRDBJ. Kemudian untuk s is tempola pukulan rapa'ijuga sama dengan sistem dan pola pukulan rapa'i pada GRDBJ. Sebagai kelompok kesenian yang menjunjung nilai Islam, Alat musik yang digunakan oleh anak-anak GRDBJB memprioritas kan praktik yang erat kaitannya dengan nilai-nilai religius. Perbedaan lain antara GRDBJ dengan GRDBJB ini jug a terdapat pada lagu yang dibawakan, yaitu untuk anak-anak biasanya menyanyikan Shalawat Nabi dan beberapa lagu dengan tingkatan yang sedang. Sedangkan lagu yang dibawakan GRDBJ adalah lagu khusus, berupa kisahkis ah yang menyesuaikan dengan konteks pertunjukan.

Tabel 1. Inventaris Perlengkapan GRDBB dan GRDBJB

\begin{tabular}{|l|l|l|l|l|}
\hline No & $\begin{array}{l}\text { Nama } \\
\text { Perlengkapan }\end{array}$ & Ukuran & Kegunaan & Jumlah \\
\hline 1 & Rapa'i & Ring 14 & Latihan & 12 Buah \\
\hline 2 & Rapa'i & Ring 17 & Pertunjukan & 12 Buah \\
\hline 4 & Kostum & Dewasa & Pertunjukan & $\begin{array}{l}12 \\
\text { Pasang }\end{array}$ \\
\hline 5 & Rencong & Sedang & $\begin{array}{l}\text { Pertunjukan } \\
\text { debus }\end{array}$ & 3 Bilah \\
\hline
\end{tabular}

(Sumber: Wawancara dengan Hamidan dan Zulkarnain. 2020)

\section{KESIMPULAN DAN SARAN 1.Kesimpulan}

Pelaku pertunjukan rapa'i daboh yang terhimpun dalam Grup Rapa'i Daboh Bungong Jeumpa Bantimoh merupakan masyarakat yang mendiami kawasan pemukiman Pasca Tsunami Aceh, CARE. Dalam kondisi sosio-geografis yang berubah yang juga berdampak pada kondisi ekonomi, mas yarakat tersebut mampu mendirikan kelompok kes enian dan mengelola dengan cukup baik, tanpa bantuan pendanaan fasilitas dan sokongan dana kesenian dari pemerintah dan dinas
Gorga : Jurnal Seni Rupa

Volume 09 Nomor 02 Juli-Desember 2020

p-ISSN: $2301-5942$ | e-ISSN: 2580-2380

terkait. Mereka secara mandiri menghidupkan GRDBJ dan GRDBJB secara swakelola, kolektif. dan s wadaya masyarakat. Kedua grup tersebut dikelola dengan menerapkan perpaduan tatakelola modern dan tradis ional yang khas. Hasil dari komitmen pengelolaan tersebut juga dapat dilihat dengan dibentuknya gup asuh atau grup cabang, berupa kelompok anak-anak sebagai generasi muda yang mewarisi tradisi yang teelah hidup dan berkembang cukup lama di Aceh ters ebut.

\section{Saran}

Di tengah kondisi sosio-geografis yang berubah akibat perpindahan Pasca Tsunami Aceh yang melanda sebagian besar daerah di Aceh kurang lebih enambelas tahun yang lalu. Kondisi tersebut juga dirasakan oleh sebagian besar masyarakat yang menghuni kawasan Pulau Aceh yang terdampak oleh tsunami. Kondisi tersebut mengharuskan mas yarakat Pulau Aceh untuk mengungsi ke beberapa tempat yang disediakan oleh pemerintah, LSM, maupun dinas terkait. Perpindahan tersebut tentunya turut memengaruhi kehidupan sosial ekonomi mas yarakat yang semulanya mengantungkan hidup dari hasil laut dan perkebunan di tempat asalnya.

Keterbatasan ekonomi selama di pemukiman dan kampung yang baru, mengharuskan pengurus GRDBJB terus bertahan dengan mengupayakan agar keduagnup rapa'i yang merupakan milik masyarakat dari Pulau Aceh ini tetap hidup dan berkembang.

Ada beberapa saran yang nantinya dapat menjadi masukan dan pertimbangan bagi dinas dan lembaga terkait, yakninya: agar lebih memiliki perhatian lebih terhadap kehidupan dan kelangsungan kelompokkelompok kesenian tradisi Aceh, dengan mengadakan program-program serta alokasi anggaran untuk fasilitas pendukung bagi Grup Rapa'i Daboh Bungong Jeumpa Bantimoh dan kesenian-kesenian tradisi lainnya sebagai bentuk dukungan terhadap proses pemajuan kebudayaan.

\section{DAFTAR RUJUKAN}

Ediwar, et.al. (2015). Rekonstruksi dan Revitalisasi Kesenian Rapa'i Aceh Pasca Tsunami. Padangpanjang: ISI Padangpanjang Press.

Hurgronje, C. Snouck. (2020). Orang Aceh: Ilmu Pengetahuan, Sastra, Permainan, dan Agama. Yogyakarta:Penerbit Mata Bangsa.

Idria, Reza. (2014). Dua Penggung Pertunjukan di Aceh: dari Konflik Negara ke Politik Syariat, dalam Seni Pertunjukan Indonesia Pasca Orde Baru. Yogyakarta: Penerbit Universitas Sanata Darma. 


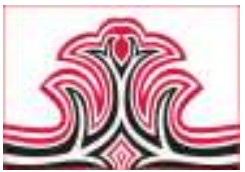

Gorga : Jurnal Seni Rupa

Volume 09 Nomor 02 Juli-Desember 2020 p-ISSN: 2301-5942 | e-ISSN: 2580-2380

Jazuli, M. (2014). Manajemen Seni Pertunjukan Edisi

2. Yogy akarta: Graha Ilmu.

Lindsay, Jennifer (ed.). (2006). Telisik Tradisi:

Pusparagam Pengelolaan Seni. Jakarta:

Yayas an Kelola.

Moleong, Lexy J. (1995). Metodologi Penelitian

Kualitatif, Bandung: PT. Remaja

Rosdakarya. 